\title{
Predictors of Ascetic Fluid Infection in Cirrhotic Patients
}

\author{
Ghada Moustafa Kamal Galal ${ }^{(1)}$, Ramy M. Elsharkawy ${ }^{(1)}$ \\ Sherif Abdelaziz Said ${ }^{(2)}$, Moataz Ibrahim Moustafa Alkadi ${ }^{(3)}$
}

1) Department of Tropical medicine and Gastroenterology,Sohag University.

2) Department of clinical pathology, Sohaguniversity.

3)Sohag Fever Hospital

\begin{abstract}
AIM: The aim of this study is to evaluate the diagnostic and prognostic value of serum Hs-CRP and platelet indices (mean platelet volume and platelet distribution width) in cirrhotic patients with clinical suspicion of spontaneous bacterial peritonitis.
\end{abstract}

\section{Introduction}

Ascites is the most common complication of cirrhosis that leads to hospital admission. Patients with liver cirrhosis are usually prone to develop bacterial infections primarily ascitic fluid infection (AFI) which is present in 15-20\% of them (Ngamruengphong et al., 2011). Spontaneous Bacterial peritonitis (SBP) is an infection of ascitic fluid without a definitive intraabdominal source that can be surgically treated (Such and Runyon, 1998). Spontaneous bacterial peritonitis (SBP) is diagnosed by testing of ascitic fluid obtained by abdominal paracentesis. A polymorphonuclearleucocytic (PMNs) count $\geq 250$ cells $/ \mathrm{mm}^{3}$ has been considered the gold standard in SBP diagnosis as it is a highly sensitive diagnostic marker (Wiest et al., 2012). An early start of antibiotic therapy is important for the successful treatment of SBP and has been shown to reduce mortality and improve survival (Hoefs et al., 1982). Therefore, there has been considerable interest in the development of a bedside test that can diagnose SBP rapidly. The development of such a test also might facilitate patient selection for further diagnostic tests or admission to a hospital and improve the cost effectiveness of SBP diagnosis.

Role of High Sensitive- CRP (Hs-CRP) as a marker of inflammation has been extensively studied in coronary artery disease and is also being studied in other conditions like chronic liver diseases, collagen vascular diseases, inflammatory arthritis and liver diseases. Hs-CRP has been studied as an inflammatory marker in infective hepatitis, alcoholic liver diseases, cirrhosis, and SBP (Lazzarotto et al., 2013). Studies have supported the view that CRP levels increase in decompensated cirrhosis and infections in cirrhosis (Cervoni et al., 2012). Moreover, it has been shown that HsCRP is of a good prognostic value in patients with cirrhosis (Fujimoto et al., 1999).

Platelet indices; Mean Platelet Volume (MPV) and Platelet Distribution Width (PDW) were found to be helpful in diagnosis of patients with AFI earlier in the course of disease progression. They are cheap, rapid and easily applicable tests, and they were significantly increased in cirrhotic patients with AFI compared with cirrhotic patients without AFI (Khorshed et al., 2015). 
Aims of the work:

The aims of our study are:

1- To evaluate the diagnostic and prognostic value of serum Hs-CRP in cirrhotic patients with clinical suspicion of spontaneous bacterial peritonitis.

2- To investigate the diagnostic and prognostic value of platelet indices (mean platelet volume and platelet distribution width) in cirrhotic patients with clinical suspicion of spontaneous bacterial peritonitis.

\section{Patients and methods}

The present study included 60patients(24females and 36 males) withliver cirrhosis and ascites with clinical suspicion of SBP. Their ages ranged between (38-75 years). Allpatients were referred to the Department of Tropical Medicine andGastroenterology, Sohag University Hospital (in the period from January 2017 to December 2017). Control group composed of 30 adult age and sex matched healthy individuals (with no evidence of liver disease or any acute or chronic illness) were also included.

Methods:The following steps were performed for all participants:

History taking, Clinical examination Investigations included:

(1) Laboratory:A) Full blood count, B) Liver profile, C)Hepatitis markers

D) Measurement of Hs-CRP in the serum:

Measured by ELISA (Monobindinc , lake forest, CA 92630, USA, Accubind, Elisa microwells). Hs-CRP has traditionally been used to diagnose and monitor acute inflammation, it was named as such for ability to bind and precipitate the C-polysaccharide of pneumococcus, Hs CRP is synthesized in the liver and is normally present as a trace constituent of serum or plasma at levels less than 0,3 mgldl, it has numerous physiological functions similar to those to those of immunoglobulin and acts as a host defence mechanism (Kimberly et al., 2003).

Hs-CRP is of a good prognostic value in patients with cirrhosis(Fujimoto et al., 1999).

E) Determination of Platelet indices; Mean Platelet Volume (MPV) and Platelet Distribution Width (PDW) :

Platelet indices; Mean Platelet Volume (MPV) and Platelet Distribution Width (PDW) were found to be helpful in diagnosis of patients with AFI earlier in the course of disease progression. They are cheap, rapid and easily applicable tests and they were significantly increased in cirrhotic patients with AFI compared with cirrhotic patients without AFI (Khorshed et al., 2015).

(2) Abdominal ultrasonography (using Siemens G50):

The following data were recorded:

Liver size ,Liver echogenicity, Portal vein diameter and patency, Splenic size .

Paracentesis:The diagnosis of spontaneous bacterial peritonitis was established by an ascitic fluid PMNL count $>250$ cells $/ \mathrm{mm} 3$, with an absence of findings suggesting secondary peritonitis.

\section{Statistical analysis:}

Data was analyzed using STATA intercooled version 12.1. Quantitative data was represented as mean, standard deviation, median and range. Data was analyzed using ANOVA for comparison of the means of three groups with Bonferroni post hoc test for comparison between each pair. Qualitative data was presented as number and percentage and compared using Chi square test. Roc curve analysis was used to detect best 
cut off of different variables that predict SBP. Sensitivity, specificity, positive predicted value and negative predictive value were also calculated. Odds ratios were obtained from logistic regression analysis.

\section{Results}

According to the results of ascetic fluid study the studied patients were classified into 3 groups:

Group 1: 24 patients (definite SBP): who had symptoms and signs of SBP and ascitic fluid neutrophils $\geq 250$ cells $/ \mathrm{mm}^{3}$.

Group 2: 24 patients (probable SBP): who had symptoms and signs suggestive of SBP but their ascitic fluid study showed neutrophils $<250$ cells $/ \mathrm{mm}^{3}$.

Group 3: 12 patients (no SBP) who had no clinical or laboratory evidence of SBP.

Table:Shows comparison of the two studied groups of patients regarding (MPV), (PDW), (HS-CRP) and (ESR). We found statistically significant differences between the two groups in all 4 markers $(\mathrm{p}<0.0001,<0.0001$ and 0.0001$)$. All markers were significantly higher in liver cirrhosis than control.

\begin{tabular}{|l|l|l|l|}
\hline Variable & $\begin{array}{l}\text { Liver cirrhosis } \\
\text { N=60 }\end{array}$ & $\begin{array}{l}\text { Controls } \\
\mathbf{N = 3 0}\end{array}$ & P value \\
\hline MPV & $11.06 \pm 2.54$ & $7.87 \pm 1.37$ & $<0.0001$ \\
Mean \pm SD & $7.1(6-10.6)$ & \\
Median (range) & $10.2(7.59-16)$ & & \\
\hline PDW & & $10.39 \pm 0.50$ & $<0.0001$ \\
Mean \pm SD & $17.21 \pm 0.67$ & $10.35(9.6-11.5)$ & \\
Median (range) & $17.5(15-17.9)$ & & \\
\hline HS-CRP & & $0.22 \pm 0.07$ & 0.0001 \\
Mean \pm SD & $21.86 \pm 17.78$ & $0.2(0.1-0.3)$ & \\
Median (range) & $18.35(0.18-56.4)$ & & \\
\hline
\end{tabular}

Table :Comparison between patients with liver cirrhosis and controls as regards MPV, PDW and HS-CRP

\section{Discussion}

Ascitic fluid infection (AFI) is a common and severe complication in cirrhotic ascitic patients (Volk and Marrero,2006), Spontaneous bacterial peritonitis (SBP) has a raised rate of morbidity and mortality, occurring in $10 \%$ to $30 \%$ of cirrhotic patients with ascites, and is associated with a very high rate of recurrence (Runyon,2009), Early detection of SBP is important as the mortality rate among untreated patients is around 50\% (Wong et al., 2008).

The most common marker of infection is an ascitic fluid PMN cell count of
$250 / \mathrm{mm}^{3}$ or higher (Gasparyan et al., 2011).MPV is significantly increased in cirrhotic patients with SB (Abdel-Razik et al.,2014), which is considered as an indicator of platelet activation (Rimola et al.,2000).

PDW is one of platelets indices increase in cirrhotic patients with AFI compared with cirrhotic patients without AFI and are were found to be helpful in diagnosis of patients with AFI earlier in the course of disease progression(Khorshed et al., 2015).

Studies have supported that (hs-CRP) levels increases in decompensated 
cirrhosis and infections in cirrhosis (Haye et al., 2011) and its role as a prognostic marker in cases of cirrhotic ascites with SBP (Lin et al., 2002) andwas significantly increase in the SBP group versus non SBP group (pretoZamperli et al., 2014).

\section{Summary and Conclusion}

Ascitic PMNL increase with peritoneal infection or with other intra-abdominal inflammatory condition, the diagnosis of SBP is established with PMNL more than $250 / \mathrm{mm}$.

Our result show that platelet indices; (MPV) (PDW) and (HS CRP) are helpful in diagnosis of SBP in cirrhotic patients. They are cheap, rapid and easily applicable tests and theyare significantly increased in cirrhotic patients with AFI compared with cirrhotic patients without AFI.

In conclusionthe best predictors for diagnosis of SBP in cirrhotic patient are the measurement of serum HS CRP, determination of MPV and PDW.

\section{References}

1. Ngamruengphong $S$, Nugent $K$, RakvitA, Parupudi S, (2011): potential preventability of spontaneous bacterial peritonitis. Dig Dis Sci 56: 2728-2734.

2. Wiest R, Krag A, Gerbes A (2012): Spontaneous Bacterial Peritonitis: Recent Guidelines and Beyond. Gut61: 297-310.

3. Lazzarotto C, Ronsoni MF, Fayad L et al. (2013): Acute phase protein for the diagnosis of bacterial infection and prediction of mortality in acute complications of cirrhosis. Ann Hepatol12 :431-439.

4. Cervoni JP, Thevenot T, Weil D et al. (2012): High Sensitive C- reactive protein predicts short-term mortality in patients with cirrhosis. J Hepatol, 6:1299-1304.

5. Khorshed SE, Ibraheem HA, Awad SM et al. (2015): Macrophage inflammatory protein-1 Beta (MIP-1 $\beta$ ) and platelet indices as predictors of spontaneous bacterial peritonitis. Open Journal of Gastroenterology 5: 94-102.

6. Volk M, Marrero J. (2006): Advances in critical care hepatology. Minerva Anestesiol; 72:269-281.

7. Runyon B (2009): AASLD Practice Guidelines Committee. Management of adult patients with ascites due to cirrhosis: an update. Hepatology; 49:2087.

8. Wong C, Holroyd-Leduc J, Thorpe K, Straus $S$ et al. (2008): Does this patient have bacterial peritonitis or portal hypertension? How do perform a paracentesis and analyze the results? JAMA; 299:1166-1178.

9. Gasparyan A, Ayvazyan L, Mikhailidis D, Kitas G et al. (2011): Mean platelet volume: a link between thrombosis and inflammation? Curr Pharm Des; 17:47-58.

10. Abdel-Razik, AhmedaEldars, WaleedbRizk, et al. (2014): Platelet indices and inflammatory markers as diagnostic predictors for ascitic fluid infection. European journal of gastroenterology \&hepatology, Volume 26.Issue 12- p1342-1347.

11. Rimola A, García-Tsao G, Navasa M, Piddock LJ, Planas R, Ber-nard B, Inadomi JM et al. (2000): Diagnosis, treatment and prophylaxis of spontaneous bacterial peritonitis: a consensus document. International Ascites Club. J Hepatol, 32: 142-53.

12. -Lin ZY, Chuang W, Dai CY et al. (2002): Clinical application of $\mathrm{C}$ reactive protein Measurement in the detection of bacterial infection in patients with liver cirrhosis.Kaohsiung $\mathrm{J}$ Med Sci, 18:121-26.

13. Preto-Zamperini M, Farhat SC, Perondi MB , PestanaAP, Cunha PS, Pugliese R P et al. (2014): Elevated CReactive Protein and Spentanous Bacterial Peritonitis in Children with Chronic Liver Disease and Ascites. 
Journal of Pediatric Gastroenterology \& Nutrition, 58, 96-98.

14. Hoefs JC, Canawati HN, Sapico FL, et al. (1982): Spontaneous bacterial peritonitis. Hepatology 2:399 - 407 .
15. Such J, Runyon B (1998): Spontaneous bacterial peritonitis. Clin Infect Dis 27: 669-674 